\title{
Intoxicated eyewitnesses: the effect of a fully balanced placebo design on event memory and metacognitive control
}

Julie Gawrylowicz

Alan Scoboria

Rachel Teodorini

lan P. Albery

This is the peer reviewed version of the following article: Intoxicated eyewitnesses: the effect of a fully balanced placebo design on event memory and metacognitive control, which has been published in final form at https://doi.org/10.1002/acp.3504.

This article may be used for non-commercial purposes in accordance with Wiley Terms and Conditions for Self-Archiving. 


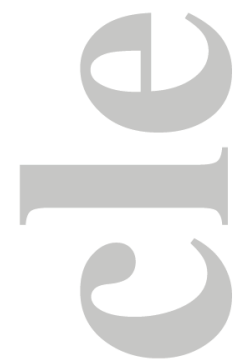

\title{
Intoxicated eyewitnesses:
}

\section{The effect of a fully balanced placebo design on event memory and metacognitive} control.

Julie Gawrylowicz, Department of Psychology, School of Social and Health Sciences, Abertay University, Dundee, UK

Alan Scoboria, Department of Psychology, University of Windsor, Ontario, Canada

Rachel Teodorini and Ian P. Albery, Division of Psychology, London South Bank University,

\author{
London, UK
}

Correspondence concerning this article should be addressed to Julie Gawrylowicz,

Department of Psychology, School of Social and Health Sciences, Abertay University, Bell

Street, Dundee, DD1 1HG, UK

\section{Acknowledgments}

The authors acknowledge research assistance by Gaby Luscombe and Hafeza Baksh.

The project was funded by a BA/Leverhulme Small Research Grant.

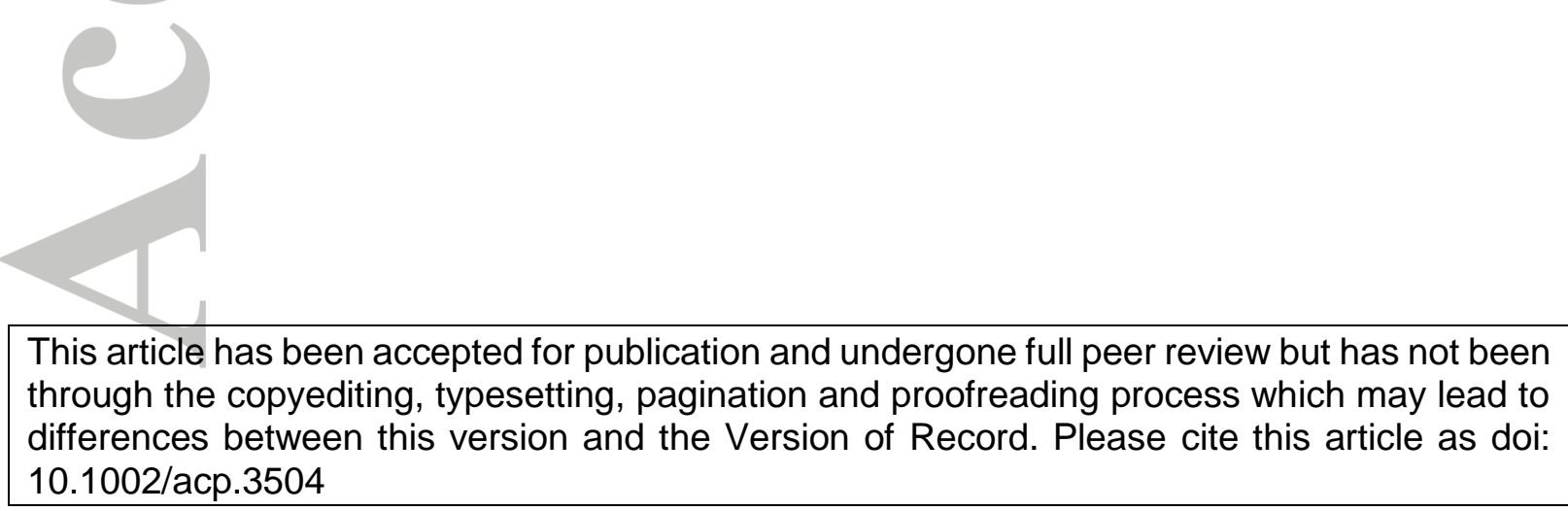




\begin{abstract}
Few studies have examined the impact of alcohol on metacognition for witnessed events. We used a $2 \times 2$ balanced placebo design, where mock-witnesses expected and drank alcohol, did not expect but drank alcohol, did not expect nor drank alcohol, or expected but did not drink alcohol. Participants watched a mock-crime in a bar-lab, followed by free recall and a cuedrecall test with or without the option to reply 'don't know' (DK). Intoxicated mock-

witnesses' free recall was less complete but not less accurate. During cued-recall, alcohol led to lower accuracy, and reverse placebo participants gave more erroneous and fewer correct responses. Permitting and clarifying DK responses was associated with fewer errors and more correct responses for sober individuals; and intoxicated witnesses were less likely to opt out of erroneous responding to unanswerable questions. Our findings highlight the practical and theoretical importance of examining pharmacological effects of alcohol and expectancies in real-life settings.
\end{abstract}

Keywords: Eyewitness Memory, Alcohol, Expectancies, Metacognitive Control, Don’t Know Responses, Placebo 
In $20 \%$ of all UK violent incidents victims reported that they were under the influence of alcohol (CSEW 2013/14), and 56.3\% of US police officers indicated that dealing with intoxicated witnesses is common (with $12.5 \%$ indicating 'very common'; Evans \& Schreiber Compo, 2009). A survey by Crossland, Kneller and Wilcock (2018) with UK police officers revealed that the victim was drunk at the time of the crime for $43.96 \%$ of interviews per month. Given this high prevalence of alcohol in the context of forensic interviewing, researchers have started to examine the impact of alcohol on eyewitness event recall, but few studies have explored the impact of alcohol on metacognitive aspects of remembering events. This is an important oversight to the extent that an individual's recall performance is a reflection of both memory retrieval and metacognitive monitoring and control processes (Koriat \& Goldsmith, 1996). The aim of the present study was to examine the impact of alcohol on mock-witnesses' event recall and metacognitive control in a fully balanced placebo design, where participants expected and received alcohol (alcohol group), expected but did not receive alcohol (placebo group), did not expect but received alcohol (reverse placebo group), or did not expect and did not receive alcohol (control group).

\section{Alcohol and eyewitness event recall}

Research examining the impact of alcohol on eyewitness recall has provided equivocal evidence - with some studies claiming that the inebriated are less reliable witnesses than those sober and other studies showing no alcohol-related memory deficits (see Hildebrand Karlén, 2018 for a review of related literature). The majority of lab-based studies have found that alcohol intoxication does not affect recall accuracy (Crossland, Kneller \& Wilcock, 2016; Hagsand, Roos af Hjelmsäter, Granhag, Fahlke \& Söderpalm Gordh, 2013, 2017; Hildebrand Karlén, Roos af Hjelmsäter, Fahlke, Granhag \& Söderpalm Gordh, 2015, 2017; La Rooy, Nicol \& Terry, 2013; Schreiber Compo et al., 2012). Some studies have shown that as alcohol dosage increases recall quantity decreases (Altman, Schreiber Compo, McQuiston, Hagsand \& 
Cervera, 2018; Hagsand et al., 2013; Hildebrand Karlén et al., 2017; Flowe et al., 2015; Thorley \& Christiansen, 2018; Yuille \& Tollestrup, 1990), whereas other studies failed to show an effect of alcohol on recall completeness (Crossland et al., 2016; LaRooy, Nicol \& Terry, 2013; Schreiber Compo et al., 2012). In addition to dosage, other important factors to consider are recall format and gender. Hagsand et al. (2017) contrasted free and cued-recall performance and found a negative alcohol-related effect on completeness only during free recall. Hildebrand Karlén et al. (2015) showed that reports by intoxicated women were less complete when compared to sober women, but no differences in completeness were obtained for men.

A small number of studies have explored the impact of alcohol on eyewitness recall outside the laboratory (e.g., in real bars) (Altman et al., 2018; Crossland et al., 2016; Van Oorsouw et al., 2012, 2015). Quasi-experimental research conducted in real-life settings has the advantage that memory can be tested under the influence of higher doses of alcohol, which is often not achievable in the lab for ethical reasons. Studies by Van Oorsouw and colleagues $(2012,2015)$ recorded peak BACs of .24\% and $.26 \%$, whereas laboratory research typically aims to reach BACs of $0.08 \%$, the UK drink-drive limit. Consistent with the majority of lab research, most quasi-experimental research has shown a decrease in correct details recalled with increasing alcohol intake (Altman et al., 2018; Crossland et al., 2016; Van Oorsouw et al., 2012, 2015). Findings related to recall accuracy are more varied in reallife settings. Van Oorsouw and colleagues $(2012,2015)$ reported decreased accuracy rates with increased intoxication, whereas Crossland et al. (2016) found no between group differences for accuracy. It is notable that Van Oorsouw et al. $(2012,2015)$ examined mocksuspects' event recall, which might be inherently different from mock-witness recall, due to different levels and types of involvement in events.

In addition to recall completeness (i.e. total number of details) and accuracy (i.e. 
correct details recalled divided by total details recalled ${ }^{1}$ ), research has started to investigate intoxicated witnesses' ability to successfully control their memory output by withholding answers to questions by replying don't know (DK) instead. Research on witness memory not involving alcohol shows that encouraging DK responding can lead to enhanced mock-witness identification evidence (Weber \& Perfect, 2012) and recall (Scoboria \& Fisico, 2013).

Schreiber Compo et al. (2011) found that placebo participants gave more DK responses compared to intoxicated and sober participants when questioned about an interaction in a bar environment. The authors theorised that placebo participants might have paid special attention to any memory failures due to the expectancy that alcohol would disrupt memory performance. This elevated vigilance might have resulted in adopting a more conservative report criterion, resulting in increased DK responding. Subsequent alcohol and eyewitness memory research failed to support this idea. Schreiber et al. (2012) found no group differences for the number of DK responses provided when recalling a simulated theft, yet others have found that as alcohol levels increased so did the number of DK responses (Altman et al., 2018; Crossland et al., 2016; Flowe et al., 2015). This study sought to contribute to this line of literature by examining how clarifying the meaning of DK responses in the intoxicated is related to memory quality.

Scoboria, Mazzoni and Kirsch (2008) observed that the meaning of DK responses in the context of questioning is ambiguous. When making a DK response a person may mean: 1) that they cannot provide an answer because they have no recollection as to whether the information was or was not present, 2) that the information needed to answer the question was not present, or 3) that the information needed to answer the question was present but cannot be recalled. Thus, DK responses, when clarified, can convey important information

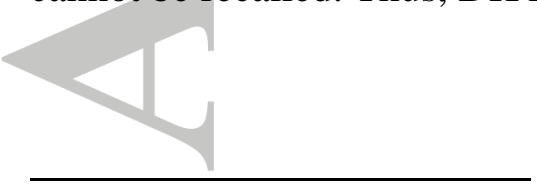

\footnotetext{
${ }^{1}$ Most studies (including the current research) exclude or separate subjective statements/information, which is unverifiable, such as participant's opinion, e.g. "she is pretty", when analysing recall accuracy.
} 
about the contents of memory, and when the meaning of DK responses is clarified accuracy and output rates may change, as demonstrated by Scoboria and Fisico (2013). Participants answered a set of answerable and unanswerable questions about a mock-crime and later explained what they meant when they chose to respond DK. After DK clarifications where taken into account and the other variables were adjusted accordingly, output and accuracy rates increased.

To recap, alcohol has no effect or only a small effect on episodic memory reports when tested using low to moderate doses in the lab. Higher levels of alcohol intoxication undermine the completeness of eyewitness accounts and to a lesser degree accuracy rates. Intriguingly, memory performance potentially changes when DK responses are examined.

\section{Memory and alcohol-related theoretical frameworks}

\section{Pharmacological effects and Alcohol Myopia Theory}

Wixted (2004) proposed that alcohol has a negative impact on memory formation and consolidation due to closing off the encoding of incoming information. This view accounts for the often reported and observed anterograde amnesic effects of alcohol (see Lister, Eckardt, \& Weingartner, 1987), with the most severe form of anterograde amnesia being the 'alcohol blackout' (Nash \& Takarangi, 2011; Wetherill \& Fromme, 2016).

A widely used cognitive theory to explain memory deficits in the intoxicated is alcohol myopia theory (AMT) (Steele \& Joseph, 1990). AMT assumes that intoxication leads to a reduction in cognitive capacity with attentional resources remaining captured by the most central or salient cues. Research testing this framework has produced mixed findings.

Schreiber Compo et al. (2011) found that intoxicated participants recalled fewer peripheral details compared to sober participants, with no differences for central details. Harvey, Kneller and Campbell (2013) found that alcohol increased eye fixations on central regions of a crime scene at encoding, which was associated with an overall decrease in details reported. Van 
Oorsouw and Merkelbach (2013) found that recall of central details was undermined by intoxication, and to a greater extent than peripheral details. Crossland et al., (2016) found no alcohol-mediated differential recall for central versus peripheral details in a lab study and a field study. Taken together, empirical evidence does not clearly support AMT and other cognitive models may be more suitable to explain differences in performance. In particular, it might be that the less complete and accurate event reports provided by inebriated witnesses are not due to encoding or storage, but rather due to differences in metacognition at retrieval.

\section{Alcohol and Metacognition}

According to Koriat and Goldsmith's (1996) strategic regulation of memory framework, memory performance is a reflection of both memory retrieval and metacognitive monitoring and control processes. What witnesses report is a combination of retrieved information, their degree of confidence in the information that comes to mind, and what of this information they are willing to report. It is proposed that when people recall an event they monitor the quality of each item of information that comes to mind, assign a level of confidence, and apply a control threshold to determine whether the level of confidence is sufficient to output the item of information. The greater the emphasis that is placed on response accuracy, the more selective people become in reporting resulting in less complete but more accurate reports (Goldmith, Koriat \& Weinberg-Eliezer, 2002).

Limited research has examined how alcohol impacts metacognitive processes when witnessed events are remembered (Evans et al., 2017; Nelson, McSpadden, Fromme \& Marlatt, 1986; Nelson, Graf, Dunlosky, Marlatt, Walker, \& Luce, 1998). Unravelling such mechanisms is of high practical and theoretical importance as it will help to illuminate whether alcohol-induced memory deficits are related to encoding, storage, metacognitive factors at retrieval, or a combination of these. Nelson et al. (1986) showed that alcohol did affect memory performance on general-knowledge questions, but that it did not impact 
metacognitive processes as measured via confidence ratings and feeling-of-knowing (FOK) judgments (e.g. how likely are you to recognise the correct answer from a group of alternatives?). Subsequently, Nelson et al. (1998) asked sober and intoxicated participants to learn word pairs and to provide confidence ratings and judgements-of-learning (JOLs) (i.e. whether previously studied items would be recalled later). Inebriated participants remembered fewer pairs and provided lower JOLs and confidence ratings. Given that the Nelson et al. studies targeted different types of memory (for word pairs or general knowledge) it is difficult to compare findings and to draw applied conclusions. More recently, Evans et al. (2017) found that intoxication did not affect metacognitive processes as measured via confidence and FOK judgments on a cued-recall test. However, on a recognition test confidence discriminated significantly better between accurate and inaccurate responses in a sober than in an intoxicated group. Taken together there is some evidence that metacognitive monitoring is affected by intoxication. Nelson et al. (1998) showed lower JOLs and confidence in inebriated participants and Evans et al. (2017) found that alcohol negatively impacted confidence calibration.

\section{Hypervigilance Hypothesis}

A vast body of research has demonstrated that alcohol-outcome expectancies can influence different behaviours and cognitions such as impulsivity (Caswell, Morgan \& Duka, 2013), self-perception (Begue, Bushman,Zerhouni, Subra, Ourabah, 2012), motor performance (Vogel-Sprott, 1995) and speed of mental processing (Fillmore, Carscadden, \& Vogel-Sprott, 1998), even in the absence of actual alcohol consumption. The hypervigilance hypothesis proposes that when individuals believe that they have been drinking they become hypervigilant to compensate for anticipated poorer performance (Testa et al., 2006). This might lead to superior performance in placebo participants (those who think they have consumed alcohol but have not) compared to intoxicated and control participants. 
Compensatory behaviours due to negative alcohol-related expectancies, were first reported by Fillmore and Vogel-Sprott (1996) using a motor-performance task. Expectations of half of the intoxicated participants were manipulated by informing them about the negative effects of alcohol on performance. The intoxicated group who received the expectation manipulation showed significantly less performance impairment than the intoxicated group who did not receive the expectation manipulation (Fillmore \& Vogel- Sprott, 1996). Similar findings were obtained using a reaction time task (Fillmore \& Blackburn, 2002).

Schreiber Compo et al., (2011) sought to use the hypervigilance hypothesis to explain increased DK responding in placebo participants, but did not find that consumption of a placebo influenced correct memory performance. This is in line with other research that failed to find superior performance in placebo participants (Crossland et al., 2016; Schreiber Compo et al., 2012; Thorley \& Christiansen, 2018; Yuille \& Tollestrup, 1990). The present research sought to further explore alcohol expectancy effects by using a fully balanced placebo design. Including a placebo group as well as a reverse placebo group (participants told they would not receive alcohol when in fact they did) enabled us to separate physiological from psychological expectancy effects.

\section{The current study}

The aim of the present study was to add to the growing body of literature on the impact of alcohol on eyewitness event recall and to extend research on the impact of intoxication on metacognitive control processes in more naturalistic settings. To our knowledge, this is the first study using a fully balanced placebo design to investigate alcohol- and expectancyrelated differences in metacognitive control in an eyewitness context. A free recall test was employed to assess mock-witnesses' event recall. To examine metacognitive control, participants engaged in a two-phase cued-recall procedure: cued-recall (questioning) without a 'don't know' (DK) option followed by cued-recall (the same questions) with a DK option. 
In line with previous alcohol and eyewitness memory research we expected to find that intoxicated participants (alcohol and reverse placebo group) would report less

information than sober participants (control and placebo group) during free recall, without an associated decrease in accuracy. For the cued-recall without DK option we hypothesised fewer correct answers by inebriated participants (alcohol and reverse placebo) due to the negative pharmacological effects of alcohol on memory encoding and consolidation. For the cued-recall with DK option we expected more liberal control thresholds leading to reduced memory accuracy in intoxicated participants compared to sober ones. Finally, we expected intoxicated participants to provide more DK responses compared to sober ones (e.g. Altman et al., 2018; Crossland et al., 2016).

\section{Method}

\section{Participants and Design}

One hundred and twenty-nine participants completed the study. The sample included 40 males and 88 females, aged 18 to 59 years $(M=28.58, S D=10.09)$. One participant did not provide information on gender or age. Participants received course credits or a monetary reward (£10) for their participation. The study utilised a 2 (expectancy: expected alcohol vs. did not expect alcohol) x 2 (alcohol: received alcohol vs. did not receive alcohol) between subjects design. The dependent measures were performance on the free recall test and the cued-recall test. Additionally, DK clarifications were obtained from participants. The study was approved by the London South Bank University's Ethics Committee and the University of Windsor Research Ethics Board.

\section{Materials}

Breath alcohol measurement. A Lion Alcolmeter 500 breathalyzer was used to measure breath alcohol content (BrAC) and converted into BAC (blood alcohol concentration) with the Lion Units Converter. 
Video. To add authenticity to the study, the to-be-remembered film depicted a staged drink spiking scene with an implied sexual assault toward the end. The simulated event took place in a bar that resembled the testing environment. The crime itself is one commonly reported to take place in pub environments (Office for National Statistics, 2018). In the video a young girl is approached by a man, who then spikes her drink and drags her towards a toilet. There is a gap in the action, and at the end the girl is seen lying semi unconscious and dishevelled on the toilet floor with her dress pulled down to one side and her bra strap showing. It is important to note that the video did not depict any actual sexual assault, but suggests that this likely happened between camera shots. This video has been used in previous eyewitness memory studies (Gawrylowicz, Memon \& Scoboria, 2014; Gawrylowicz, Memon, Scoboria, Hope \& Gabbert, 2014). The event was presented on a laptop computer with a 12.1-inch screen, native resolution $1024 \times 768$, with 24 bit $(16.7 \mathrm{~m}$ colours) colour support.

Free recall. Participants were provided with a form instructing them to write down everything they could remember about the video. The free recall was completed in writing to minimise interviewer bias. Recent research suggests that written memory accounts of mockcrimes are not inferior to spoken accounts, and that both writing and speaking are appropriate methods to elicit complete and accurate reports (Sauerland, Krix, van Kan, Glunz \& Sak, 2014).

Cued-recall test. To examine metacognitive control we employed an adapted version of Pansky, Goldsmith, Koriat and Pearlman-Avnion's (2009) two-phase forced-free paradigm (hereinafter referred to as cued-recall without and with 'don't know' (DK) option). Cuedrecall questions were presented in written format and participants had to answer them in writing. The same 24 questions were asked in each phase (14 answerable and 10 plausible unanswerable questions). Answerable questions asked about information presented in the video (e.g. "What was the name of the bar?"; the name was visible early in the video). 
Unanswerable questions asked about information that was not present but plausible (e.g. "What was the name of the woman in the green dress?" when her name was never mentioned). The use of both types of questions mirrors real-life settings in which interviewers typically do not know what occurred/was witnessed when they choose questions to ask. In the cued-recall without DK option participants provided an answer to each question, even if they had to guess. In the cued-recall with DK option participants were presented with the same questions again but this time they were given the option to withhold responses by replying "I don't know". Finally, participants were asked to clarify any DK responses by providing them with four options: 1) truly do not know (no recollection of occurrence or non-occurrence for the information queried); 2) information was not provided in the video (hereafter not present); 3) information was provided in the video but the details needed to answer the question could not be remembered (hereafter present not remembered); or, 4) anything else (no additional categories emerged). This procedure allowed us to measure the following: 1) Number of accurate answers to cued-recall questions without DK option - a measure of information that is accessible in memory.

2) Completeness and accuracy of answers to cued-recall questions with DK option a reflection of a combination of memory and metacognitive processes. Typically, when metacognition is effective a trade-off between quantity (i.e. completeness) and quality (i.e. accuracy) of information is observed (Koriat \& Goldsmith, 1996). People predominantly 'withhold' responses about which they are less certain resulting in less complete (i.e. fewer details overall) but more accurate (i.e. fewer errors) reports.

3) Responses to answerable and unanswerable questions - responses to answerable questions indicate how effectively information has been encoded and can be recalled. Responses to unanswerable questions show how well respondents can identify when information is not available in memory. Various authors argue that memory for occurrence 
and memory for non-occurrence require different metamemory strategies (Mazzoni \& Kirsch, 2001; Strack and Bless, 1994).

5) Clarified Don't Know responses - When making a DK response a person may mean: 1) that they cannot provide an answer, because they have no recollection as to whether the information was or was not present, 2) that the information needed to answer the question was not present, or 3) that the information needed to answer the question was present but cannot be recalled. These types of clarifications convey important information about the contents of memory and may change accuracy and output rates (Scoboria \& Fisico, 2013).

Alcohol administration. Administration took place in a purpose-built bar-laboratory (see below). Vodka, orange juice and tonic were used to make the beverages dependent on condition.

Distractor exercises. The Cognitive Failures Questionnaire (Broadbent, Cooper, Fitzgerald \& Parkes, 1982), the Coopersmith Self-Esteem Inventory (Coopersmith, 1967), the Eysenck Personality Questionnaire (both long and short versions (Eysenck \& Eysenck, 1975; Eysenck \& Wilson, 1994)), the State Trait Anxiety Inventory (Spielberger, Gorsuch,

Lushene, Vagg \& Jacobs, 1983) and freely available online word-searches were presented as distractor tasks. Data from these tasks was not further analysed.

\section{Procedure}

Screening phase. Participants were recruited via posters displayed around the University campus, the SONA system (an online survey manager) and a call for subjects via the University's news feed. Interested individuals then contacted the research team regarding participation in the study and were provided with a comprehensive screening questionnaire via email to establish their eligibility to participate. The following inclusion criteria applied:

1) Over 18 years of age; 2) Not pregnant; 3) A score of 21 or less on the Alcohol Use Disorders Identification Test (AUDIT; Babor, Higgins-Biddle, Saunders \& Monteiro, 2001), 
indicating no current problematic use of alcohol. The following exclusion criteria applied: 1 ) Active or unstable medical or psychiatric conditions; 2) Current prescription medication where alcohol is contraindicated; 3) Drug/alcohol dependence or ever been treated for substance dependence; 4) Presence of violence/aggression, severe mental health problems and/or self-harm. In addition, individuals provided information about their age, weight, and height for later alcohol dose calculations. Once the researchers were satisfied that potential participants met the criteria for the study they were invited to take part in the experimental phase.

Experimental phase. To imitate real-world conditions, testing took place in a purpose built bar-laboratory designed to simulate a British pub (e.g. public house décor, a 3.6m long bar dressed with beer taps, stools, a fruit machine, optics, etc.). After providing written informed consent, participants were randomly assigned to one of the four experimental conditions: alcohol $(n=33)$; placebo $(n=33)$; reverse placebo $(n=31)$; and control $(n=32)$. Next the alcohol administration commenced. Prior to beverage consumption a mouthwash (cool mint flavour) was given for the purpose of disguising the presence or absence of vodka. Dose of alcohol and soft drink to achieve a BAC of approximately $0.06 \%$ were calculated using a computerised formula based on gender, height and weight (see Curtin, 2000). Drinks were poured out of the sight of participants. Participants were asked to consume their beverage in no less than 20 minutes and no longer than 30 minutes. Drinking time was monitored by the experimenter and when necessary participants were encouraged to drink more slowly or faster depending on their actual drinking behaviour. After finishing the beverage participants rinsed their mouths with water and completed filler tasks for 15 to 30 minutes to allow BAC levels to increase and peak. Participants were breathalysed (but not informed of the reading) 15 minutes post consumption and, if the $\mathrm{BAC}<0.06 \%$, a second reading was taken 15 minutes later. The mock-crime video was presented between 20 and 35 
minutes after completion of drinking and verification of BAC. The video was followed by 30 minutes of distractor measures. If distractor tasks were completed within the 30-minute period further word search puzzles were given. Memory of the mock-crime was then assessed via free recall. Participants were given as much time as they needed to complete this task. Free recall was followed by the cued-recall procedure and DK clarifications. No feedback about performance was provided at any point. Finally, participants were informed about the actual nature of their drink and fully debriefed. Those displaying BACs above .08\% (the UK drink-drive limit) were asked to remain in the lab until their BACs decreased below this level. Those who did not wish to stay behind signed a waiver confirming their awareness of being in excess of the UK drink drive limit.

Coding. A coding scheme containing 407 visible details depicted in the video was used for coding the free recall test (see Gawrylowicz et al., 2014). Coders were instructed to monitor the coding scheme while coding the information provided in the written free recalls. A detail was deemed correct if it was present in the video and correctly described (i.e. in agreement with the coding scheme). A detail was coded as error if it was in disagreement with the coding scheme (e.g. she was wearing a blue dress, when in fact she was wearing a green dress). Confabulations refer to reported details that were not present in the video (e.g. stating that the perpetrator wore a hat, when in fact he wore no hat). Details were only coded once. Any additional correctly reported details that were not yet in the coding scheme were added progressively. Accuracy rates were calculated by dividing the number of correct details reported by the number of details reported in total. Subjective statements such as "She looked pretty", were not coded and nor were included in further analysis. Reliability was established by double coding $20 \%$ of the transcripts (Pearson correlations for correct details, $r=.908, p<$ .001 ; errors, $r=.922, p<.001$; confabulations: $r=.934, p<.001)$. Details were further categorised into person (e.g. the girl had brown hair), action (e.g. the man drank wine), 
location (e.g. the man dragged her into the toilet) and object details (e.g. the girl played with her phone) as per Stein and Memon (2016). Responses to the cued-recall test were coded as correct, error and DK using a coding template including the correct answers. DK clarifications were coded as outlined in the method section.

\section{Results}

\section{Blood Alcohol Concentration}

All BrACs were converted to BACs with a blood: breath ratio of 2300:1. On the first breathalyser reading BACs for the alcohol (mean $=.06 \%, S D=.02 ; 95 \%$ CI $[.05, .07])$ and the reverse placebo groups $($ mean $=.06 \%, S D=.02 ; 95 \%$ CI $[.05, .07])$ did not differ statistically, $t(61)=.98, p=.33, d=.24$. All participants who did not consume alcohol (control, placebo) recorded BACs of .00\%.

\section{Analysis of free recall data}

Group differences in free recall were analysed by comparing group mean differences, overlap in $95 \%$ confidence intervals, and calculating and interpreting confidence intervals on standardized effect sizes (unbiased Cohen's d), following the procedures recommended by Cumming (2014). Sampling distributions for variables were obtained by bootstrapping 1000 samples to estimate confidence intervals on group means and mean differences. To test whether alcohol and expectancy impacted eyewitness reports the primary dependent variable of interest from the free recall phase of the study was overall (total) details reported.

There was an effect of alcohol, with inebriated participants recalling fewer details compared to sober participants, $M_{\text {diff }}=14.98[95 \%$ CI 7.14, 22.82]; $d=.67[.31,1.02]$. No effect of expectancy was observed, $M_{\text {diff }}=.07(-8.56,7.97), d=.01[-.36, .33]$, and based on the pattern of group means there was no evidence of an interaction.

We also explored correct, erroneous and confabulated details to better understand the components that contributed to total recall. For correct details, there was an effect of alcohol 
with inebriated participants recalling fewer correct details compared to sober participants, $M_{\text {diff }}=14.34[95 \%$ CI $6.74,21.94] ; d_{u n b}=.66[.30,1.01]$. No effect of expectancy was observed for correct responses, $M_{\text {diff }}=.05[-7.96,8.06], d_{u n b}=.00[-.34, .34]$, and based on the pattern of group means there was no evidence of an interaction.

There were no statistically significant effects associated with the number of errors or confabulations made during free recall, in part because both occurred infrequently. Accuracy was generally high (above 95\%) and no effects of condition or expectancy were present.

Thus, while intoxicated individuals reported fewer details overall due to providing fewer correct details, the information that intoxicated individuals provided was not less accurate.

\section{Recall of specific types of details}

Correct, incorrect and confabulated details made during free recall were further classified according to the categories of person, action, object and location details (Table 2; see Holliday et al., 2012). Significant main effects of alcohol were observed on the number of correct details for persons $\left(M_{\text {diff }}=3.26[95 \% \mathrm{CI} .18,6.34], d_{\text {unb }}=.37[.02, .72]\right)$, actions $\left(M_{\text {diff }}\right.$ $\left.=4.53[1.95,7.11], d_{u n b}=.61[.26, .96]\right)$, objects $\left(M_{\text {diff }}=3.74[1.74,5.74], d_{u n b}=.65[.30\right.$, $1.00])$, and locations $\left(M_{d i f f}=2.81[1.17,4.45], d_{u n b}=.59[.24, .95]\right)$. No effect of expectancy or interaction were found for these variables. There were no statistically significant effects for erroneous or confabulated person, action, object or location details. Thus, consuming alcohol reduced the number of correct details recalled regardless of type of detail.

\section{Analysis of cued-recall test data}

Cued-recall without DK option. For answerable questions, drinking and expecting

alcohol interacted. Individuals who drank without being told that they were drinking (reverse placebo group) produced the lowest accuracy compared to the other three groups (see Figure 
1, Panel $1 ; M_{\text {diff }}=.14\left[95 \% \mathrm{CI}_{\text {diff }}[.07, .19], d_{\text {unb }}=.94[.51,1.37]\right)$. The group difference for accuracy was influenced by a higher error rate $\left(M_{\text {diff }}=1.86,[1.02,2.68], d_{\text {unb }}=.93[.50\right.$,

1.36] $)$ and a lower correct response rate in the reverse placebo group $\left(M_{\text {diff }}=1.88,[1.04\right.$, $\left.2.71], d_{u n b}=.93[.50,1.36]\right)$ compared to the other groups, which did not differ statistically.

No statistically meaningful effects for unanswerable questions were found. Correct responses to unanswerable questions were few. This is because participants must identify and reject unanswerable questions by making spontaneous responses such as "that was not there" rather than guessing (which they were instructed to do here) (see Table 3 for group means).

Cued-recall with DK option. Across all groups, participants provided an average of 11.10 [95\% CI 10.22, 11.95] DK responses to the 24 questions, reflecting a substantial decrease in output. Providing participants with the DK option was associated with fewer correct responses $\left(M_{\text {diff }}=1.39[1.01,1.76], d_{\text {unb }}=.66[.47, .85]\right)$ and errors $\left(M_{\text {diff }}=4.14[3.77,4.51]\right.$, $\left.d_{u n b}=1.80[1.54,2.09]\right)$ to answerable questions, and fewer errors to unanswerable questions $\left(M_{\text {diff }}=5.60[5.23,5.97], d_{\text {unb }}=2.82[2.44,3.23]\right)$. Commensurately, accuracy to answerable questions increased when DK responses were permitted $\left(M_{\text {diff }}=.09[.06, .11]\right), d_{\text {unb }}=.49$ $[.25, .74])$. Accuracy to unanswerable questions increased slightly from statistically zero during cued-recall without DK option $(M=.02[95 \% \mathrm{CI} .00, .03])$ to statistically slightly higher than zero during cued-recall with DK option $(M=.03[.01, .05])$; due to the fact that very few participants made any correct responses to unanswerable questions during the cuedrecall without DK option. Thus, participants successfully used the DK option to regulate the quality of their output.

Drinking alcohol was associated with fewer DK responses to unanswerable questions (see Table 4 for group means; $M_{\text {diff }}=1.63[.68,2.58], d=.59[.24, .95]$ ). No effects of experimental condition were found for DK responses to answerable questions. Individuals who drank alcohol without being informed (reverse placebo) produced the lowest accuracy to 
answerable questions compared to the other three groups (Figure 1, panel 2; $M_{\text {diff }}=.16,[.08$, $\left..25], d_{u n b}=.83[.40,1.25]\right)$. This was influenced by the interactions of alcohol and expectancy producing more errors (Figure 2, panel 1; $\left.M_{\text {diff }}=1.02[.02,1.75], d_{\text {unb }}=.38[.04, .73]\right)$ and fewer correct responses in the reverse placebo group compared to the remaining three groups, which did not differ (Figure 2, panel 2; $M_{\text {diff }}=1.69[.88,2.50], d_{u n b}=.87[.44,1.30]$ ). There were no statistically meaningful effects or interactions in responding to unanswerable questions for the cued-recall test with DK option.

In summary, allowing DK responses resulted in the withholding of primarily erroneous responses; and intoxicated participants were less likely to withhold responses to unanswerable questions.

\section{Clarifying DK responses}

Correct and error rates were recoded based on the clarified DK responses as per the procedure in Scoboria and Fisico (2013). "Not present" responses were recoded as correct when made to unanswerable questions and error when made to answerable questions. "Present not remembered" responses were recoded as error when made to unanswerable questions, and correct when made to answerable questions. These were combined with the original correct and error rates, and adjusted accuracy rates were also calculated (see Table 5 for adjusted values). These clarified responses are indicative of the ability to identify whether information was provided in the original video, and to improve performance by avoiding responding to questions that do not have an answer.

Participants who drank alcohol were less likely to clarify DK responses as "not present" $\left(M_{d i f f}=1.66[.60,2.71], \mathrm{d}=.54[.20, .90]\right)$; and, albeit not statistically significant, 
less likely to clarify DK responses as "present not remembered" $\left(M_{\text {diff }}=.77[-.02,1.56], d=\right.$ $.34[-.01, .69])$.

Drinking alcohol was associated with lower accuracy to answerable $\left(M_{d i f f}=.08[.02\right.$, $.15], d=.43[.08, .77])$ and unanswerable questions $\left(M_{\text {diff }}=.17[.08, .26], d=.63[.27, .98]\right)$, more errors to unanswerable $\left(M_{\text {diff }}=1.5[.61,2.39], d=.58[.23, .94]\right)$ and answerable questions $\left(M_{\text {diff }}=.95[.11,1.79], d=.39[.04, .74]\right)$, and fewer correct responses to unanswerable $\left(M_{\text {diff }}=1.69[.87,2.51], d=.72[.36,1.08]\right)$ and answerable questions $\left(M_{\text {diff }}=\right.$ $1 . \overline{41}[.54,2.28], d=.56[.21, .92])$. This final effect was qualified by an interaction that emerged for the adjusted variables. Alcohol and expectancy interacted to predict adjusted correct responses for answerable questions. Participants who drank and did not expect alcohol made fewer correct responses to answerable questions than the other three groups combined $\left(M_{\text {diff }}=1.84[.82,2.87], d=.75[.32,1.17]\right)$.

(<smiles>C1CC2CC12</smiles>

\section{Discussion}

The current study is the first to explore the impact of alcohol on memory and metacognitive control using a fully balanced placebo design in an eyewitness memory paradigm. In addition to extending previous applied research findings on the impact of alcohol on eyewitness memory reports, the present research provides new insights into metacognitive control processes (in the form of DK responses) that might contribute to explaining how alcohol influences the quality of information retrieved by intoxicated witnesses.

\section{Alcohol and free recall}

In line with some previous research on alcohol and witness memory, the free recall reports provided by our intoxicated mock-witnesses were less complete than those by sober individuals (e.g. Altman et al., 2018; Flowe et al., 2015; Hildebrand Karlén et al., 2017; 
Yuille \& Tollestrup, 1990). Also consistent with other work was the finding that information provided by intoxicated individuals was not less accurate and accuracy rates were generally high across conditions (see Hagsand et al., 2017). This is contrary to the common belief often held by lay people and justice professionals, that alcohol consumption impairs memory accuracy, thus undermining intoxicated victim and witness credibility (Evans \& Schreiber Compo, 2009; Kassin, Tubb, Hosch \& Memon, 2001; Schreiber Compo et al., 2012). Such mistaken beliefs may lead to discounting accurate testimonies by witnesses and victims, thereby missing potentially important investigative leads that could jeopardise the success of the whole criminal investigation. In the long-run this may have a detrimental effect on the crime resolution rate and increase the risk of new crimes.

We found that alcohol consumption was associated with fewer correct details recalled regardless of detail type (i.e. person, action, object or location). To our knowledge only three other studies have examined the type of detail recalled from a mock-crime by intoxicated individuals (Hildebrand Karlén et al., 2015; Read, Yuille \& Tollestrup, 1992; Schreiber Compo et al., 2011). Unfortunately, but not surprisingly, all studies used slightly different coding procedures, which makes comparisons of findings more difficult. Hildebrand Karlén et al. (2015) sorted items into actions (what was done), verbal statements (what the actors said), thoughts/feelings (participants' perceptions of the actors' thoughts/feelings), objects (concrete items in the mock crime), and subjective evaluations (participants' value-laden comments regarding the actors, their behaviours or the scene). They found that intoxicated women recalled fewer action details and subjective evaluations. Schreiber Compo et al. (2011) examined subjective, action and conversational details reported by intoxicated individuals and found that intoxicated individuals recalled more subjective evaluations. Read et al. (1992) used a similar coding procedure to the one adopted in our study, dividing responses into action, object, and person details. They reported that alcohol impaired the 
recall of person details and to a lesser degree the recall of action and object details.

Differences in findings may also be related to the stimulus materials used. Whereas in our study participants observed a video of a crime, in Read et al.'s (1992) study participants committed a simulated theft as mock-perpetrators and interacted with a confederate. It may be that individuals pay different attention to different types of details depending on their role and involvement during mock-crime scenarios, i.e. as perpetrator, witness, or victim.

\section{Alcohol expectancies}

Using a balanced placebo design allowed us to explore the impact of alcohol expectancies on eyewitness event recall and to separate them from the pharmacological effects of alcohol consumption. Few eyewitness memory studies have used a balanced placebo design and most of these have tested eyewitness identification performance rather than event recall (e.g. Colloff \& Flowe, 2016; Flowe et al., 2017). These studies did not find any alcohol-related expectancy effects on identification performance or associated confidence judgments. Our data indicate that expectancies about alcohol consumption do not impact mock-witnesses' free recall performance. However, during cued-recall participants who drank alcohol whilst not expecting alcohol appeared to produce significantly more errors and fewer correct responses compared to the other three experimental groups. So why did the reverse placebo group perform so poorly? It could be argued that drinking alcohol without being aware resulted in reduced vigilance when encoding the video as participants did not anticipate any detrimental alcohol-related effects. Relatedly, at retrieval they might have paid less attention to the potential for memory errors compared to those participants who were told that they had consumed alcohol. It is important to note that these explanations are speculative and further research into how awareness of drinking alcohol might impact memory performance at encoding and retrieval is required. 
Importantly the alcohol by expectancy interactions suggest that pharmacological effects of alcohol alone are not sufficient to explain episodic memory deficits in intoxicated mock-witnesses. Individuals' beliefs about drinking or not drinking alcohol do affect the quality of reports. Such findings may be relevant when considering the amount of alcohol consumed at the time of witnessing events and whether individuals are aware of the amount consumed. Future research that examines interactions between drinking alcohol and expectations about drinking alcohol might consider measuring beliefs about the quantity consumed.

\section{Alcohol and metacognitive control}

DK responses frequently occur in real-life investigative interviewing situations and allowing them can have both positive as well as negative effects (Scoboria et al., 2008). Permitting DK responses may lead to less complete memory accounts. On the other hand, allowing individuals to opt out of questions can increase accuracy by providing respondents with the opportunity to omit answers about which they are less certain (Koriat \& Goldsmith, 1996), or to avoid responding to questions that have no answer based on what was witnessed (Scoboria \& Fisico, 2013). From a criminal investigative point of view, encouraging DK responses is preferable, as accuracy is often more important than detailed but incorrect witness statements.

According to Koriat and Goldsmith (1996), DK responses reflect metacognitive control processes. Scoboria et al. (2008) showed that one-third of DK responses were actually statements about information not being present indicating that DK replies often have the potential to convey more information than is initially revealed. Furthermore, recoding DK responses can lead to subsequent changes in accuracy estimates (Scoboria et al., 2008). As expected, in the current study accuracy rates to cued-recall questions increased when permitting DK responses at the expense of memory output (i.e. the number of questions 
answered). Thus, individuals successfully used the DK option to control the quality of their memory output.

For answerable questions non-intoxicated individuals (regardless of whether they were told that they had received alcohol) and intoxicated individuals who believed they had consumed alcohol showed higher accuracy when DK responses were permitted compared to those who drank but were told that they did not drink alcohol (reverse placebo group). For unanswerable questions intoxicated individuals made more errors and provided fewer DK responses than sober ones. So, intoxicated mock-witnesses were less likely to use the DK option to withhold erroneous responses to unanswerable questions. In line with research on alcohol intoxication and risk-taking (Lane, Cherek, Pietras \& Tcheremissine, 2004), intoxication might have led to the adoption of more liberal control thresholds in the form of fewer DK responses leading to reduced report quality. An alternative explanation is provided by the source-monitoring framework (Johnson, Hashtroudi \& Lindsay, 1993). Johnson et al. (1993) proposed that alcohol might undermine reflective processes thereby limiting sourcemonitoring abilities. The limited research available supports this idea. For example, Paraskevaides et al. (2010) found impaired source-monitoring in intoxicated individuals when using a word recognition task. Similarly, Hartzler and Fromme (2003) found poorer source memory in intoxicated participants during a process-dissociation task. In our study, participants' responses to the cued-recall test without DK were necessarily nearly entirely erroneous. During the cued-recall with DK option, it seems likely that some of these confabulated responses came to mind, which participants needed to reject as originating from a source other than the video. Intoxication may impair an individual's ability to effectively reject initial erroneous responses. Future research should explore the extent to which acute alcohol intoxication might impact source-monitoring in more applied contexts that can be directly related to eyewitness scenarios. 
Our findings are in contrast to earlier research examining the impact of alcohol on DK responding (Altman et al., 2018; Flowe et al., 2015; Schreiber Compo et al., 2011; 2012). While Schreiber Compo et al. (2012) found no alcohol-related differences in the number of DK responses reported, Schreiber Compo et al. (2011) did find increased DK responses in placebo participants, but no difference between their alcohol and control group. Yet others observed increased DK responding in intoxicated participants (Altman et al., 2018; Flowe et al., 2015). We found that drinking alcohol was associated with fewer DK responses but only for unanswerable questions. That is, in situations where answering I don't know would have been preferable, because the information in question was not provided, intoxicated individuals were less likely to use this option. Further examination of DK clarifications confirms that intoxicated individuals used DK responses less often to indicate nonoccurrence. Methodological differences might account for these discrepancies in findings. Recall format often varied. Schreiber Compo et al. (2011) asked participants to report everything they could remember. Altman et al. (2018) and Schreiber Compo et al. (2012) initiated free recall with open-ended questions (e.g. "Please tell me everything that you remember about the person's face."), followed by open-ended cued questions about more specific details (e.g. "What did his/her face look like?"). Flowe et al. (2015) used a recognition test to assess memory performance. We examined DK responses towards very specific cued-recall questions and usage of DK responses might differ depending on the question format utilized.

\section{Applied Implications}

This study was designed to mirror certain elements of an intoxicated eyewitness incident in a bar in a controlled lab setting. The laboratory, as well as the stimulus material used, included props typically found in British pubs, thereby creating a setting that is likely to evoke expectations associated with drinking alcohol and intoxication. Our findings indicate 
that intoxicated witnesses and victims provide more accurate free recall reports than people typically believe. The intoxicated mock-witnesses in this study provided less complete event reports under free recall instructions that were not less accurate compared to non-intoxicated individuals.

Our findings further suggest that alcohol-related expectancies may play an important role in determining the accuracy of subsequent memory accounts. The finding that intoxicated individuals who were not aware that they were drinking exhibited lower performance may not have many direct applications in the field, but they do raise further empirical questions with regards to the importance of peoples' beliefs about how much alcohol they have consumed and the impact of this on memory and metacognition. Few studies of eyewitness memory have examined intoxication in relation to expectancy. Given the many different ways that interviews are conducted and questions are structured it will be worthwhile to continue to investigate how and when alcohol expectancies influence the quality of reports. Officers in the field could consider asking witnesses and victims about their beliefs regarding the amount of alcohol consumed in addition to obtaining objective intoxication measures (e.g. breathalyzer). Together, these measures might be more revealing about an individual's ability to completely and accurately recall an event than any of them individually. In addition, we advocate more standardized procedures within and across police forces regarding how to deal with intoxicated witnesses, which appears to be currently lacking (Crossland et al., 2018). This does not only encompass how to best adapt the police interview to appropriately accommodate intoxicated witnesses, but also how to objectively and effectively determine an individual's degree of intoxication. At present, depending on the country, officers may or may not be legally prohibited to breathalyse a witness.

The re-classification of DK responses in our research suggests intoxicated mockwitnesses exhibit problems with source-monitoring. In other words, drinking alcohol led to 
impairment in identifying what information was and was not present in the video, knowledge that is necessary in order to provide meaningful responses to questions. On an applied level, source-monitoring deficits can lead to false eyewitness statements as one might not be able to correctly recollect whether they have actually seen something or just heard about it, for instance, from a friend or via social media. In the worst-case scenario, source-monitoring errors can lead to wrongful accusations and even false confessions. Professionals working within the Criminal Justice System should be made aware (e.g. through training) of the potential negative effect of alcohol on an individual's source monitoring abilities, so that lines of questioning which are particularly problematic for individuals with sourcemonitoring deficits, such as leading questions and invitations to guess or speculate, can be avoided and/or minimised. Using appropriate interviewing techniques during criminal investigations is of the utmost importance and the present research findings suggest that this is especially the case when the witness is under the influence of alcohol.

\section{Limitations}

Our study has several limitations. First, we did not assess participants' in-the-moment beliefs about their alcohol consumption during the experiment and we thus do not have data on the effectiveness of the expectancy manipulation. We used similar procedures to other research to induce psychological expectancy effects such as telling participants that their drink did/did not contain alcohol (Flowe et al., 2016; 2017). We also asked subjects to gargle with non-alcoholic mouthwash prior to beverage consumption to supposedly improve breathalyzer readings but in reality to reduce taste acuity (Nelson, McSpadden, Fromme \& Marlatt, 1986; Gawrylowicz et al., 2017). However, it remains unclear whether our expectancy groups shared the same beliefs about the psychological and pharmacological effects of alcohol intoxication as their control and alcohol counterparts. Indeed some 
evidence exists that placebo participants might perceive themselves to be less intoxicated than participants who received alcohol (Martin, Earleywine, Finn \& Young, 1990).

Furthermore, participants may differ regarding their individual beliefs about how alcohol may impair their performance resulting in individual differences in that performance. For example, Fillmore and Vogel-Sprott (1995) showed that alcohol and placebo participants who expected greater impairment due to alcohol consumption performed more poorly on a motor skill task than individuals with less negative alcohol-related beliefs. Future research could make use of validated alcohol outcome expectancy questionnaires (e.g. Fromme, Stroot \& Kaplan, 1993) to assess the nature and degree of participants' alcohol-related beliefs. Second, although we claim to test the impact of alcohol on memory and metacognition in an applied eyewitness context, some might argue that the mock-crime video used does not create levels of arousal comparable to those experienced when witnessing a real crime. Previous research has shown that arousal plays an important role when considering the impact of alcohol on eyewitness memory performance (Read et al., 1992). Our study did not measure how emotionally arousing participants perceived the mock-crime to be and future research would benefit from collecting data regarding participants' feelings of arousal.

Third, similar to other alcohol laboratory studies we were limited to the amount of alcohol we were permitted to administer to participants. The average peak BAC achieved in the current study could be considered fairly low and future research should explore the impact of alcohol under higher intoxication levels and/or compare performance as a function of increasing BAC levels.

\section{Final Remarks}

The current findings highlight the importance of investigating pharmacological as well as expectancy effects in future empirical work testing the effects of alcohol on 
eyewitness memory performance. Whereas alcohol had little effect on the quality of eyewitness accounts under free recall conditions, during cued-recall test conditions intoxication led to more errors and fewer correct responses. Moreover, those intoxicated made more errors when questioned about non-occurrences (i.e. they were more likely to provide an answer and less likely to opt out by responding with 'I don't know' to unanswerable questions) and were less able to identify questions that could not be answered.

Together these findings illustrate the value of examining the effects of alcohol and expectancies on metacognitive regulation for witnessed events.

\section{Acknowledgements}

The project was funded by a BA/Leverhulme Small Research Grant.

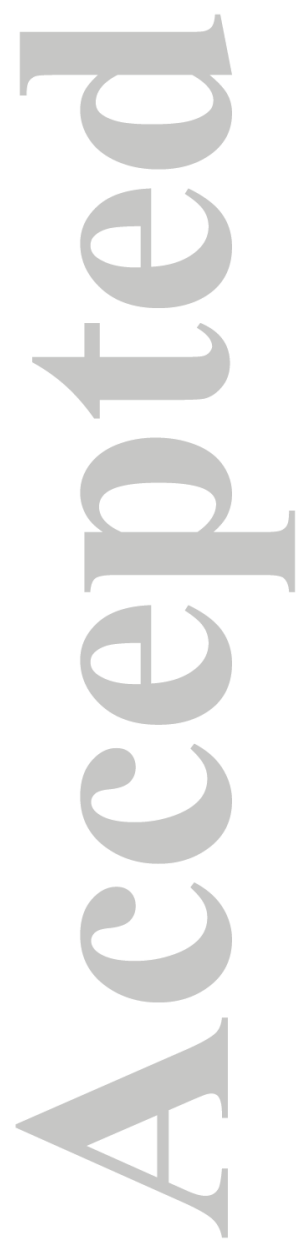




\section{References}

Altman, C. M., Schreiber Compo, N., McQuiston, D., Hagsand, A. V., \& Cervera, J. (2018). Witnesses' memory for events and faces under elevated levels of intoxication. Memory, 1-14. https://doi.org/10.1080/09658211.2018.1445758

Babor, T., Higgins-Biddle, J. C., Saunders, J. B., \& Monteiro, M. G. (2001). AUDIT. The Alcohol use disorders identification test: Guidelines for use in primary care (2nd ed.). Geneva, Switzerland: World Health Organization.

Bègue, L., Bushman, B. J., Zerhouni, O., Subra, B., \& Ourabah, M. (2013). 'Beauty is in the eye of the beer holder': People who think they are drunk also think they are attractive. British Journal of Psychology, 104(2), 225-234. https://doi.org/10.1111/j.2044$\underline{8295.2012 .02114 . x}$

Broadbent, D. E., Cooper, P. F., FitzGerald, P., \& Parkes, K. R. (1982). The cognitive failures questionnaire (CFQ) and its correlates. British Journal of Clinical Psychology, 21(1), 1-16. https://doi.org/10.1111/j.2044-8260.1982.tb01421.x

Caswell, A. J., Morgan, M. J., \& Duka, T. (2013). Acute alcohol effects on subtypes of impulsivity and the role of alcohol-outcome expectancies. Psychopharmacology, 229(1), 21-30. https://doi.org/10.1007/s00213-013-3079-8

Colloff, M. F., \& Flowe, H. D. (2016). The effects of acute alcohol intoxication on the cognitive mechanisms underlying false facial recognition. Psychopharmacology, 233(11), 2139-2149.

Coopersmith, S. (1967). The antecedents of self-esteem. San Francisco: W. H. Freeman \& Co.

Crossland, D., Kneller, W., \& Wilcock, R. (2016). Intoxicated witnesses: Testing the validity of the alcohol myopia theory. Applied Cognitive Psychology, 30(2), 270-281. https://doi.org/10.1002/acp.3209 
Crossland, D., Kneller, W., \& Wilcock, R. (2018). Intoxicated eyewitnesses: prevalence and procedures according to England's police officers. Psychology, Crime \& Law, 24(10), 979-997. https://doi.org/10.1080/1068316X.2018.1474216

\section{CSEW 2013/14}

https://www.ons.gov.uk/peoplepopulationandcommunity/crimeandjustice/compendiu $\underline{\mathrm{m} / \text { focusonviolentcrimeandsexualoffences/2015-02- }}$

12/chapter5violentcrimeandsexualoffencesalcoholrelatedviolence

Cumming, G. (2014). The new statistics: Why and how. Psychological science, 25(1), 7-29.

Curtin JJ (2000) [BAL calculator]. Unpublished computer program

Degl'Innocenti, A., \& Bäckman, L. (1999). Source memory in major depression. Journal of Affective Disorders, 54(1), 205-209. https://doi.org/10.1016/S0165-0327(98)00167-0

Evans, J. R., Schreiber Compo, N., Carol, R. N., Schwartz, B. L., Holness, H., Rose, S., \& Furton, K. G. (2017). Alcohol intoxication and metamemory: Little evidence that moderate intoxication impairs metacognitive monitoring processes. Applied Cognitive Psychology, 31(6), 573-585. https://doi.org/10.1002/acp.3373

Evans, J. R., Schreiber Compo, N., \& Russano, M. B. (2009). Intoxicated witnesses and suspects: Procedures and prevalence according to law enforcement. Psychology, Public Policy, and Law, 15(3), 194-221. https://doi.org/10.1037/a0016837

Eysenck, H. J., \& Eysenck, S. B. G. (1994). Manual for the Eysenck Personality Questionnaire: (EPQ-R Adult). San Diego, CA: Educational Industrial Testing Service.

Eysenck, H. J. \& Wilson, G. D. (1975). Know your own personality. London: Temple Smith

Fillmore, M. T., \& Blackburn, J. (2002). Compensating for alcohol-induced impairment: alcohol expectancies and behavioral disinhibition. Journal of Studies on Alcohol, 63(2), 237-246. https://doi.org/10.15288/jsa.2002.63.237 
Fillmore, M. T., \& Vogel-Sprott, M. (1995). Expectancies about alcohol-induced motor impairment predict individual differences in responses to alcohol and placebo. Journal of Studies on Alcohol, 56(1), 90-98. https://doi.org/10.15288/jsa.1995.56.90

Fillmore, M. T., \& Vogel-Sprott, M. (1996). Evidence that expectancies mediate behavioral impairment under alcohol. Journal of Studies on Alcohol, 57(6), 598-603. https://doi.org/10.15288/jsa.1996.57.598

Fillmore, M. T., \& Vogel-Sprott, M. (1996). Social drinking history, behavioral tolerance and the expectation of alcohol. Psychopharmacology, 127(4), 359-364. https://doi.org/10.1007/BF02806015

Fillmore, M. T., Carscadden, J. L., \& Vogel-Sprott, M. (1998). Alcohol, cognitive impairment and expectancies. Journal of Studies on Alcohol, 59(2), 174-179. https://doi.org/10.15288/jsa.1998.59.174

Flowe, H. D., Colloff, M. F., Karoğlu, N., Zelek, K., Ryder, H., Humphries, J. E., \& Takarangi, M. K. (2017). The effects of alcohol intoxication on accuracy and the confidence-accuracy relationship in photographic simultaneous line- ups. Applied Cognitive Psychology, 31(4), 379-391. https://doi.org/10.1002/acp.3332

Flowe, H. D., Takarangi, M. K., Humphries, J. E., \& Wright, D. S. (2015). Alcohol and remembering a hypothetical sexual assault: Can people who were under the influence of alcohol during the event provide accurate testimony?. Memory, 24(8), 1042-1061. https://doi.org/10.1080/09658211.2015.1064536

Fromme, K., Stroot, E. A., \& Kaplan, D. (1993). Comprehensive effects of alcohol: Development and psychometric assessment of a new expectancy questionnaire.

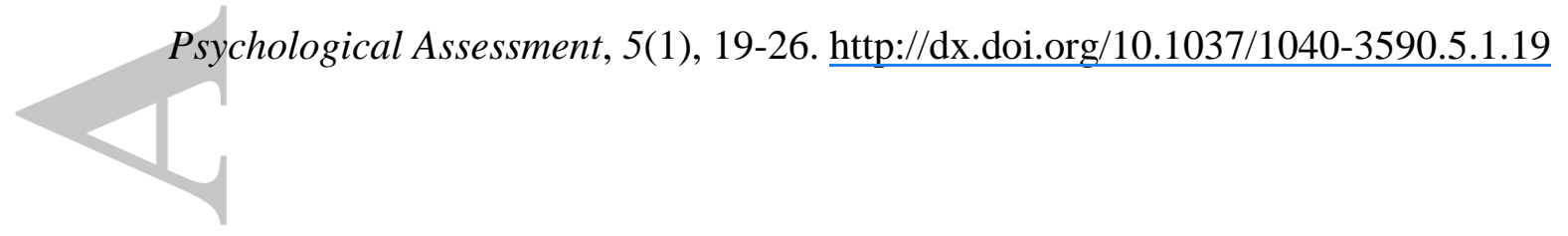


Gawrylowicz, J., Memon, A., \& Scoboria, A. (2014). Equipping witnesses with transferable skills: The Self-Administered Interview@. Psychology, Crime \& Law, 20(4), 315-325. https://doi.org/10.1080/1068316X.2013.777961

Gawrylowicz, J., Memon, A., Scoboria, A., Hope, L., \& Gabbert, F. (2014). Enhancing older adults' eyewitness memory for present and future events with the Self-Administered Interview. Psychology and Aging, 29(4), 885-890. http://dx.doi.org/10.1037/a0038048

Gawrylowicz, J., Ridley, A. M., Albery, I. P., Barnoth, E., \& Young, J. (2017). Alcoholinduced retrograde facilitation renders witnesses of crime less suggestible to misinformation. Psychopharmacology, 234(8), 1267-1275. https://doi.org/10.1007/s00213-017-4564-2

Glisky, E. L., Rubin, S. R., \& Davidson, P. S. (2001). Source memory in older adults: An encoding or retrieval problem?. Journal of Experimental Psychology: Learning, Memory, and Cognition, 27(5), 1131-1146. http://dx.doi.org/10.1037/0278$\underline{7393.27 .5 .1131}$

Hagsand, A. V., Roos af Hjelmsäter, E., Granhag, P. A., Fahlke, C., \& Söderpalm Gordh, A. (2017). Witnesses stumbling down memory lane: The effects of alcohol intoxication, retention interval, and repeated interviewing. Memory, 25(4), 531-543. https://doi.org/10.1080/09658211.2016.1191652

Hagsand, A., Roos af Hjelmsäter, E. R., Granhag, P. A., Fahlke, C., \& Söderpalm Gordh, A. (2013). Bottled memories: On how alcohol affects eyewitness recall. Scandinavian Journal of Psychology, 54, 188-195. http:// dx.doi.org/10.1111/sjop.12035

Hartzler, B., \& Fromme, K. (2003). Fragmentary blackouts: Their etiology and effect on alcohol expectancies. Alcoholism: Clinical and Experimental Research, 27(4), 628637. https://doi.org/10.1111/j.1530-0277.2003.tb04399.x 
Harvey, A. J., Kneller, W., \& Campbell, A. C. (2013). The elusive effects of alcohol intoxication on visual attention and eyewitness memory. Applied Cognitive Psychology, 27(5), 617-624. https://doi.org/10.1002/acp.2940

Hildebrand Karlén, M. (2018). Interviewing intoxicated witnesses: Memory performance in theory and practice. Scandinavian Journal of Psychology, 59(2), 113-126. https://doi.org/10.1111/sjop.12404

Hildebrand Karlén, M., Roos af Hjelmsäter, E., Fahlke, C., Granhag, P. A., \& Söderpalm Gordh, A. (2017). To wait or not to wait? Improving results when interviewing intoxicated witnesses to violence. Scandinavian Journal of Psychology, 58(1), 15-22. https://doi.org/10.1111/sjop.12345

Hildebrand Karlén, M., Roos af Hjelmsäter, E., Fahlke, C., Granhag, P. A., \& Söderpalm Gordh, A. (2015). Alcohol intoxicated eyewitnesses' memory of intimate partner violence. Psychology, Crime \& Law, 21(2), 156-171.

https://doi.org/10.1080/1068316X.2014.951644

Holliday, R. E., Humphries, J. E., Milne, R., Memon, A., Houlder, L., Lyons, A., \& Bull, R. (2012). Reducing misinformation effects in older adults with cognitive interview mnemonics. Psychology and Aging, 27(4), 1191-1203. http://dx.doi.org/10.1037/a0022031

Johnson, M. K., Hashtroudi, S., \& Lindsay, D. S. (1993). Source monitoring. Psychological bulletin, 114(1), 3-28. https://doi.org/ 10.1037/0033-2909.114.1.3

Kassin, S. M., Tubb, V. A., Hosch, H. M., \& Memon, A. (2001). On the" general acceptance" of eyewitness testimony research: A new survey of the experts. American Psychologist, 56(5), 405-416. https://doi.org/ 10.1037/0003-066X.56.5.405 
Koriat, A., \& Goldsmith, M. (1996). Monitoring and control processes in the strategic regulation of memory accuracy. Psychological review, 103(3), 490-517. https://doi.org/ 10.1037/0033-295X.103.3.490

Krix, A. C., Sauerland, M., Lorei, C., \& Rispens, I. (2015). Consistency across repeated eyewitness interviews: Contrasting police detectives' beliefs with actual eyewitness performance. PloS One, 10(2), 1-17. https://doi.org/10.1371/journal.pone.0118641

Lane, S. D., Cherek, D. R., Pietras, C. J., \& Tcheremissine, O. V. (2004). Alcohol effects on human risk taking. Psychopharmacology, 172(1), 68-77. https://doi.org/10.1007/s00213-003-1628-2

LaRooy, D., Nicol, A., \& Terry, P. (2013). Intoxicated eyewitnesses: The effects of alcohol on eyewitness recall across repeated interviews. Open Journal of Medical Psychology, 2(3), 107-114. http://dx.doi.org/10.4236/ojmp.2013.23017

Lister, R. G., Eckardt, M. J., \& Weingartner, H. (1987). Ethanol intoxication and memory. In Recent Developments in Alcoholism (pp. 111-126). Springer US.

Maisto, S. A., Palfai, T., Vanable, P. A., Heath, J., \& Woolf-King, S. E. (2012). The effects of alcohol and sexual arousal on determinants of sexual risk in men who have sex with men. Archives of Sexual Behavior, 41(4), 971-986. https://doi.org/10.1007/s10508-011-9846-x

Martin, C. S., Earleywine, M., Finn, P. R., \& Young, R. D. (1990). Some boundary conditions for effective use of alcohol placebos. Journal of Studies on Alcohol, 51(6), 500-505. https://doi.org/10.15288/jsa.1990.51.500

Mazzoni, G., \& Kirsch, I. (2002). Autobiographical memories and beliefs: A preliminary metacognitive model. Applied Metacognition, 121-145. 
Mednick, S. C., Cai, D. J., Shuman, T., Anagnostaras, S., \& Wixted, J. T. (2011). An opportunistic theory of cellular and systems consolidation. Trends in neurosciences, 34(10), 504-514. https://doi.org/10.1016/j.tins.2011.06.003

Mitchell, K. J., \& Johnson, M. K. (2009). Source monitoring 15 years later: What have we learned from fMRI about the neural mechanisms of source memory?. Psychological Bulletin, 135, 638-677. http://dx.doi.org/10.1037/a0015849

Mitchell, K. J., Johnson, M. K., \& Mather, M. (2003). Source monitoring and suggestibility to misinformation: Adult age- related differences. Applied Cognitive Psychology, 17(1), 107-119. https://doi.org/10.1002/acp.857

Moulton, P. L., Petros, T. V., Apostal, K. J., Park, R. V. 2nd, Ronning, E. A., King, B. M., \& Penland, J. G. (2005). Alcohol induced impairment and enhancement of memory: A test of the interference theory. Physiology and Behvavior, 85, 240-245.

https://doi.org/10.1016/j.physbeh.2005.03.011

Nash, R. A., \& Takarangi, M. K. (2011). Reconstructing alcohol-induced memory blackouts. Memory, 19(6), 566-573. https://doi.org/10.1080/09658211.2011.590508

Nelson, T.O., Graf, A., Dunlosky, J., Marlatt, A., Walker, D., \& Luce, K. (1998). Effect of acute alcohol intoxication on recall and on judgements of learning during the acquisition of new information. In: G. Mazzoni \& T. Nelson (Eds.) Metacognition and Cognitive Neuropsychology: Monitoring and Control Processes (pp. 161-180). Mahwah, NJ: Lawrence Erlbaum Associates Publishers.

Nelson, T.O., McSpadden, M., Fromme, K., \& Marlatt, G.A. (1986). Effects of alcohol intoxication on metamemory and retrieval from long term memory. Journal of Experimental Psychology: General, 15, 247-254. doi: 10.1037/0096-3445.115.3.247

Flatley, J. (2018). Sexual offences in England and Wales: Year ending March 2017. London, UK: Office for National Statistics. 
Palmer, F. T., Flowe, H. D., Takarangi, M. K., \& Humphries, J. E. (2013). Intoxicated witnesses and suspects: An archival analysis of their involvement in criminal case processing. Law and Human Behavior, 37(1), 54-59. https://doi.org/10.1037/lhb0000010

Pansky, A., Goldsmith, M., Koriat, A., \& Pearlman-Avnion, S. (2009). Memory accuracy in old age: Cognitive, metacognitive, and neurocognitive determinants. European Journal of Cognitive Psychology, 21(2-3), 303-329. https://doi.org/10.1080/09541440802281183

Paraskevaides, T., Morgan, C. J., Leitz, J. R., Bisby, J. A., Rendell, P. G., \& Curran, H. V. (2010). Drinking and future thinking: Acute effects of alcohol on prospective memory and future simulation. Psychopharmacology, 208(2), 301-308. https://doi.org/10.1007/s00213-009-1731-0

Parker, E. S., Birnbaum, I. M., Weingartner, H., Hartley, J. T., Stillman, R. C., \& Wyatt, R. J. (1980). Retrograde enhancement of human memory with alcohol.

Psychopharmacology, 69(2), 219-222. https://doi.org/10.1007/BF00427653

Poole, D. A., \& White, L. T. (1993). Two years later: Effect of question repetition and retention interval on the eyewitness testimony of children and adults. Developmental Psychology, 29(5), 844-853. http://dx.doi.org/10.1037/0012-1649.29.5.844

Sauerland, M., Krix, A. C., van Kan, N., Glunz, S., \& Sak, A. (2014). Speaking is silver, writing is golden? The role of cognitive and social factors in written versus spoken witness accounts. Memory \& Cognition, 42(6), 978-992.

\section{https://doi.org/10.3758/s13421-014-0401-6}

Schreiber Compo, N., Carol, R. N., Evans, J. R., Pimentel, P., Holness, H., Nichols-Lopez, K., ... \& Furton, K. G. (2017). Witness memory and alcohol: The effects of statedependent recall. Law and Human Behavior, 41(2), 202-215. 
http://dx.doi.org/10.1037/lhb0000224

Schreiber Compo, N., Evans, J. R., Carol, R. N., Kemp, D., Villalba, D., Ham, L. S., \& Rose,

S. (2011). Alcohol intoxication and memory for events: A snapshot of alcohol myopia in a real-world drinking scenario. Memory, 19(2), 202-210.

https://doi.org/10.1080/09658211.2010.546802

Schreiber Compo, N., Evans, J. R., Carol, R., Villalba, D., Ham, L., Garcia, T., \& Rose, S. (2012). Intoxicated witnesses: Better than their reputation? Law and Human Behavior, 36, 77-86. http://dx.doi.org/10.1037/ h0093951

Scoboria, A., \& Fisico, S. (2013). Encouraging and clarifying “don't know” responses enhances interview quality. Journal of Experimental Psychology: Applied, 19(1), 7282. http://dx.doi.org/10.1037/a0032067

Scoboria, A., Mazzoni, G., \& Kirsch, I. (2008). "Don't know" responding to answerable and unanswerable questions during misleading and hypnotic interviews. Journal of Experimental Psychology: Applied, 14(3), 255-265. http://dx.doi.org/10.1037/1076898X.14.3.255

Snyder, H. N., Rand, M. R., \& Sabol, W. J. (2010). Alcohol and crime: Data from 20022008. Bureau of Justice Statistics. Retrieved from https://ojprdcweb57/index.cfm?ty=pbdetail\&iid=2313

Spielberger, C. D., Gorsuch, R. L., Lushene, R., Vagg, P. R., \& Jacobs, G. A. (1983). Manual for the state-trait anxiety inventory (Palo Alto, CA, Consulting Psychologists Press). Inc.

Steele, C. M., \& Josephs, R. A. (1990). Alcohol myopia: Its prized and dangerous effects. American Psychologist, 45(8), 921-933. http://dx.doi.org/10.1037/0003$\underline{066 X .45 .8 .921}$ 
Stein, L. M., \& Memon, A. (2006). Testing the efficacy of the cognitive interview in a developing country. Applied Cognitive Psychology, 20(5), 597-605. https://doi.org/10.1002/acp.1211

Strack, F., \& Bless, H. (1994). Memory for nonoccurrences: Metacognitive and presuppositional strategies. Journal of Memory and Language, 33(2), 203-217. https://doi.org/10.1006/jmla.1994.1010

Thorley, C., \& Christiansen, P. (2018). The impact of own and others' alcohol consumption on social contagion following a collaborative memory task. Memory, 26(6), 727-740. https://doi.org/10.1080/09658211.2017.1404110

Van Oorsouw, K., \& Merckelbach, H. (2012). The effects of alcohol on crime- related memories: A field study. Applied Cognitive Psychology, 26(1), 82-90. https://doi.org/10.1002/acp.1799

Van Oorsouw, K., Merckelbach, H., \& Smeets, T. (2015). Alcohol intoxication impairs memory and increases suggestibility for a mock crime: A field study. Applied Cognitive Psychology, 29(4), 493-501. https://doi.org/10.1002/acp.3129

Wetherill, R. R., \& Fromme, K. (2016). Alcohol- induced blackouts: A review of recent clinical research with practical implications and recommendations for future studies. Alcoholism: clinical and experimental research, 40(5), 922-935. https://doi.org/10.1111/acer.13051

Wixted, J. T. (2004). The psychology and neuroscience of forgetting. Annual Review of Psychology, 55, 235-269. https://doi.org/10.1146/annurev.psych.55.090902.141555

Wixted, J. T. (2005). A theory about why we forget what we once knew. Current Directions in Psychological Science, 14(1), 6-9. https://doi.org/10.1111/j.09637214.2005.00324.x 
Yuille, J. C., \& Tollestrup, P. A. (1990). Some effects of alcohol on eyewitness memory.

Journal of Applied Psychology, 75(3), 268-273. https://doi.org/10.1037/0021-

9010.75.3.268
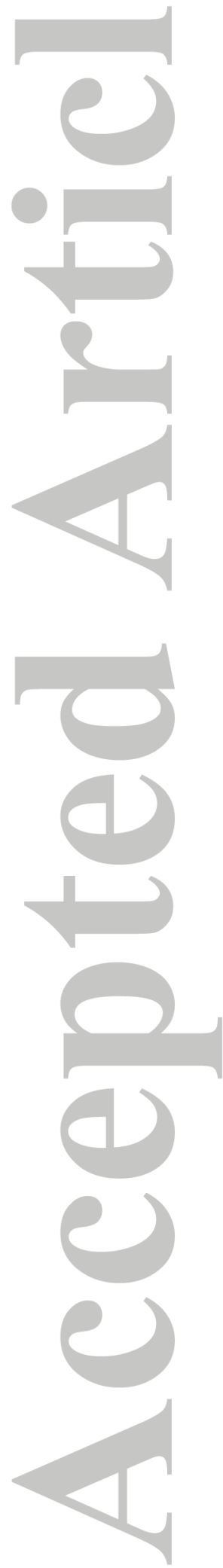
Table 1. Free Recall, Means and 95\% Confidence Intervals, by group.

\begin{tabular}{|l|c|c|c|c|}
\hline \multirow{2}{*}{} & \multicolumn{4}{|c|}{ Groups } \\
\cline { 2 - 5 } & Alcohol & Control & Reverse placebo & Placebo \\
\hline \multirow{2}{*}{ Total details } & 51.58 & 66.69 & 54.97 & 69.67 \\
& {$[42.98,60.17]$} & {$[59.95,73.42]$} & {$[47.64,62.30]$} & {$[60.30,79.03]$} \\
\hline Correct details & 50.12 & 64.34 & 53.06 & 67.48 \\
\hline Incorrect details & {$[41.84,58.58]$} & {$[57.84,70.85]$} & {$[45.80,60.33]$} & {$[58.53,76.44]$} \\
\hline $\begin{array}{l}\text { Confabulated } \\
\text { details }\end{array}$ & .97 & 1.75 & 1.48 & 1.55 \\
\hline Accuracy rate & {$[.41,1.53]$} & {$[.85,2.65]$} & {$[.89,2.08]$} & {$[.89,2.20]$} \\
\hline
\end{tabular}

Note: Alcohol (consumed and expected alcohol); Control (did not consume, did not expect alcohol); Reverse placebo (consumed alcohol, did not expect alcohol); Placebo (did not consume alcohol, expected alcohol). 
Table 2. Free Recall, Means and 95\% Confidence Intervals for correct, incorrect and confabulated details by group and detail type.

\begin{tabular}{|c|c|c|c|c|}
\hline \multirow[b]{3}{*}{ Correct person details } & \multicolumn{4}{|c|}{ Groups } \\
\hline & Alcohol & Control & Reverse placebo & Placebo \\
\hline & $\begin{array}{c}14.18 \\
{[10.76,17.60]}\end{array}$ & $\begin{array}{c}16.53 \\
{[13.92,19.14]}\end{array}$ & $\begin{array}{c}14.06 \\
{[11.19,16.93]}\end{array}$ & $\begin{array}{c}18.21 \\
{[14.54,21.89]}\end{array}$ \\
\hline Correct action details & $\begin{array}{c}16.00 \\
{[13.28,18.72]}\end{array}$ & $\begin{array}{c}21.31 \\
{[19.14,23.48]}\end{array}$ & $\begin{array}{c}18.42 \\
{[15.43,21.41]}\end{array}$ & $\begin{array}{c}22.09 \\
{[19.37,24.81]}\end{array}$ \\
\hline Correct object details & $\begin{array}{c}10.70 \\
{[8.80,12.60]}\end{array}$ & $\begin{array}{c}14.44 \\
{[12.49,16.39]}\end{array}$ & $\begin{array}{c}11.10 \\
{[9.16,13.04]}\end{array}$ & $\begin{array}{c}14.82 \\
{[12.39,17.25]}\end{array}$ \\
\hline Correct locations details & $\begin{array}{c}9.33 \\
{[7.70,10.97]}\end{array}$ & $\begin{array}{c}12.06 \\
{[10.66,13.46]}\end{array}$ & $\begin{array}{c}9.48 \\
{[7.73,11.24]}\end{array}$ & $\begin{array}{c}12.36 \\
{[10.40,14.33]}\end{array}$ \\
\hline Incorrect person details & $\begin{array}{c}.51 \\
{[.21, .82]}\end{array}$ & $\begin{array}{c}1.12 \\
{[.49,1.76]}\end{array}$ & $\begin{array}{c}.81 \\
{[.45,1.17]}\end{array}$ & $\begin{array}{c}.88 \\
{[.27,1.49]}\end{array}$ \\
\hline Incorrect action details & $\begin{array}{c}.27 \\
{[.03, .51]}\end{array}$ & $\begin{array}{c}.22 \\
{[.04, .40]}\end{array}$ & $\begin{array}{c}.36 \\
{[.03, .68]}\end{array}$ & $\begin{array}{c}.45 \\
{[.20, .71]}\end{array}$ \\
\hline Incorrect object details & $\begin{array}{c}.12 \\
{[.01, .24]}\end{array}$ & $\begin{array}{c}.22 \\
{[.04, .40]}\end{array}$ & $\begin{array}{c}.19 \\
{[.02, .37]}\end{array}$ & $\begin{array}{c}.12 \\
{[.00, .24]}\end{array}$ \\
\hline Incorrect location details & $\begin{array}{c}.06 \\
{[-.02, .15]}\end{array}$ & $\begin{array}{c}.19 \\
{[-.01, .38]}\end{array}$ & $\begin{array}{c}.13 \\
{[-.28, .29]}\end{array}$ & $\begin{array}{c}.09 \\
{[-.01, .19]}\end{array}$ \\
\hline Confabulated person details & $\begin{array}{c}.06 \\
{[-.025, .15]}\end{array}$ & $\begin{array}{c}.16 \\
{[-.03, .34]}\end{array}$ & $\begin{array}{c}.03 \\
{[-.03, .10]}\end{array}$ & $\begin{array}{c}.03 \\
{[-.03, .09]}\end{array}$ \\
\hline Confabulated action details & $\begin{array}{c}.15 \\
{[-.01, .31]}\end{array}$ & $\begin{array}{c}.19 \\
{[.02, .36]}\end{array}$ & $\begin{array}{c}.16 \\
{[-.05, .38]}\end{array}$ & $\begin{array}{c}.30 \\
{[.06, .55]}\end{array}$ \\
\hline Confabulated object details & $\begin{array}{c}.06 \\
{[-.02, .15]}\end{array}$ & $\begin{array}{c}.13 \\
{[-.08, .32]}\end{array}$ & $\begin{array}{c}.13 \\
{[.00, .25]}\end{array}$ & $\begin{array}{c}.12 \\
{[.00, .24]}\end{array}$ \\
\hline $\begin{array}{l}\text { Confabulated location } \\
\text { details }\end{array}$ & $\begin{array}{c}.12 \\
{[.00, .24]}\end{array}$ & $\begin{array}{c}.13 \\
{[.00, .25]}\end{array}$ & $\begin{array}{c}.10 \\
{[-.01, .21]}\end{array}$ & $\begin{array}{c}.18 \\
{[.04, .32]}\end{array}$ \\
\hline
\end{tabular}


Table 3. Cued-recall without DK option: Responding to answerable and unanswerable questions by group.

\begin{tabular}{|l|c|c|c|c|}
\hline & \multicolumn{3}{|c|}{ Groups } \\
\hline & Alcohol & Control & Reverse placebo & Placebo \\
\hline Answerable & & & & \\
\hline Correct & $5.58[4.89,6.27]$ & $6.16[5.45,6.86]$ & $3.94[3.22,4.65]$ & $5.70[5.01,6.39]$ \\
\hline Error & $8.39[7.71,9.08]$ & $7.84[7.15,8.54]$ & $10.03[9.33,10.74]$ & $8.30[7.62,8.99]$ \\
\hline Accuracy & $0.40[0.35,0.45]$ & $0.44[0.39,0.49]$ & $0.28[0.23,0.33]$ & $0.41[0.36,0.46]$ \\
\hline Unanswerable & & & & \\
\hline Correct & $0.21[-0.03,0.46]$ & $0.19[-0.06,0.44]$ & $0.03[-0.22,0.28]$ & $0.30[0.06,0.55]$ \\
\hline Error & $9.79[9.55,10.03]$ & $9.81[9.57,10.06]$ & $9.96[9.72,10.22]$ & $9.70[9.45,9.94]$ \\
\hline Accuracy & $0.02[-0.00,0.05]$ & $0.02[-0.00,0.04]$ & $0.003[-0.02,0.03]$ & $0.03[0.01,0.06]$ \\
\hline
\end{tabular}

Note: Group means and 95\% confidence intervals.

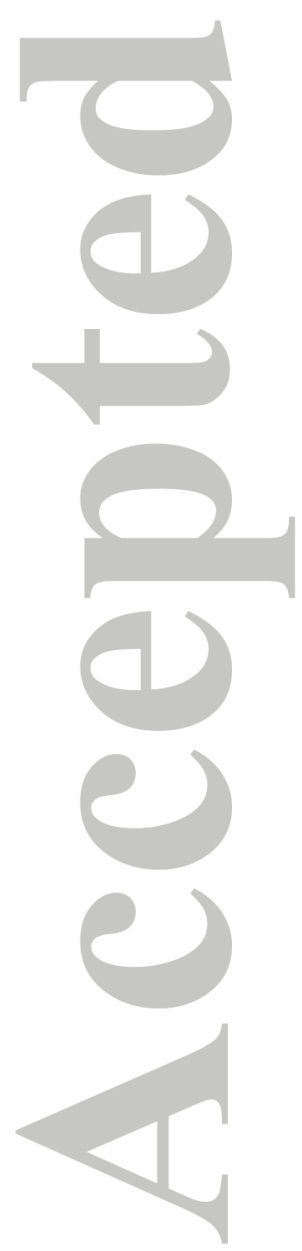


Table 4. Cued-recall with DK option responses by group.

\begin{tabular}{|l|c|c|c|c|}
\hline \multirow{2}{*}{} & \multicolumn{4}{|c|}{ Groups } \\
\hline & Alcohol & Control & Reverse placebo & Placebo \\
\hline Answerable & & & & \\
\hline Correct & $4.53[3.85,5.21]$ & $4.29[3.60,4.98]$ & $2.77[2.07,3.47]$ & $4.29[3.60,4.98]$ \\
\hline Error & $4.56[3.72,5.40]$ & $4.03[3.18,4.89]$ & $5.40[4.53,6.27]$ & $4.07[3.21,4.92]$ \\
\hline Don't know & $4.88[3.81,5.94]$ & $5.58[4.50,6.66]$ & $5.83[4.74,6.93]$ & $5.65[4.57,6.72]$ \\
\hline Accuracy & $0.51[0.44,0.58]$ & $0.52[0.45,0.60]$ & $0.35[0.28,0.43]$ & $0.50[0.43,0.57]$ \\
\hline Unanswerable & & & & \\
\hline Correct & $0.28[-0.04,0.60]$ & $0.13[-0.20,0.45]$ & $0.13[-0.20,0.46]$ & $0.29[-0.03,0.61]$ \\
\hline Error & $5.06[4.17,5.96]$ & $3.52[2.61,4.42]$ & $5.33[4.41,6.26]$ & $3.61[2.71,4.52]$ \\
\hline Don't know & $4.66[3.72,5.60]$ & $6.35[5.41,7.30]$ & $4.53[3.57,5.50]$ & $6.10[5.15,7.05]$ \\
\hline Accuracy & $0.04[-0.00,0.08]$ & $0.02[-0.03,0.06]$ & $0.02[-0.12,0.07]$ & $0.03[-0.01,0.07]$ \\
\hline
\end{tabular}

Note: Group means and 95\% confidence intervals.

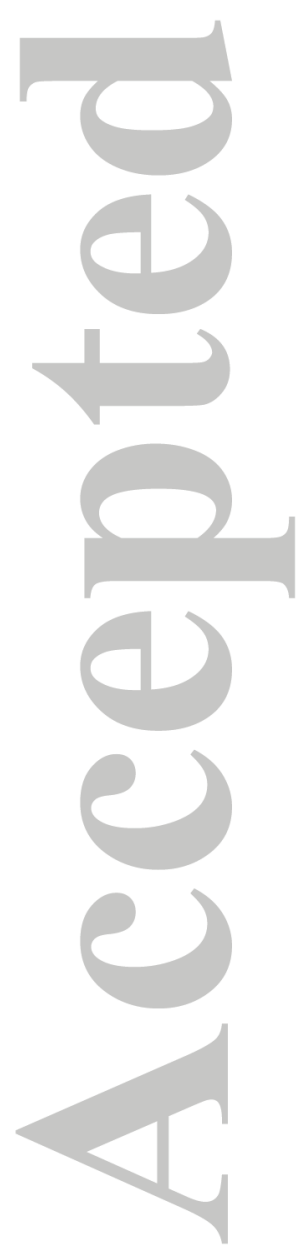


Table 5. Recoding of cued-recall with DK option variables following clarification of DK responses by group.

\begin{tabular}{|l|c|c|c|c|}
\hline & \multicolumn{3}{|c|}{ Groups } \\
\hline & Alcohol & Control & Reverse placebo & Placebo \\
\hline Answerable & & & & \\
\hline Correct & $5.88[5.04,6.72]$ & $6.72[5.87,7.57]$ & $4.36[3.49,5.22]$ & $6.39[5.56,7.23]$ \\
\hline Error & $5.61[4.78,6.44]$ & $5.28[4.44,6.12]$ & $6.55[5.69,7.41]$ & $4.94[4.11,5.77]$ \\
\hline Don't know & $2.49[1.69,3.28]$ & $1.91[1.10,2.72]$ & $3.10[2.27,3.92]$ & $2.67[1.87,3.47]$ \\
\hline Accuracy & $0.51[0.45,0.57]$ & $0.56[0.49,0.62]$ & $0.42[0.35,0.48]$ & $0.55[0.49,0.62]$ \\
\hline Unanswerable & & & & \\
\hline Correct & $3.06[2.25,3.87]$ & $5.22[4.40,6.04]$ & $3.26[2.42,4.09]$ & $4.49[3.68,5.30]$ \\
\hline Error & $5.33[4.45,6.22]$ & $3.78[2.88,4.68]$ & $5.48[4.57,6.40]$ & $4.03[3.15,4.92]$ \\
\hline Don't know & $1.61[1.03,2.18]$ & $1.00[0.42,1.58]$ & $1.26[0.67,1.85]$ & $1.49[0.91,2.06]$ \\
\hline Accuracy & $0.36[0.27,0.46]$ & $0.58[0.49,0.68]$ & $0.41[0.32,0.51]$ & $0.52[0.43,0.61]$ \\
\hline
\end{tabular}

Note: Group means and 95\% confidence intervals. 

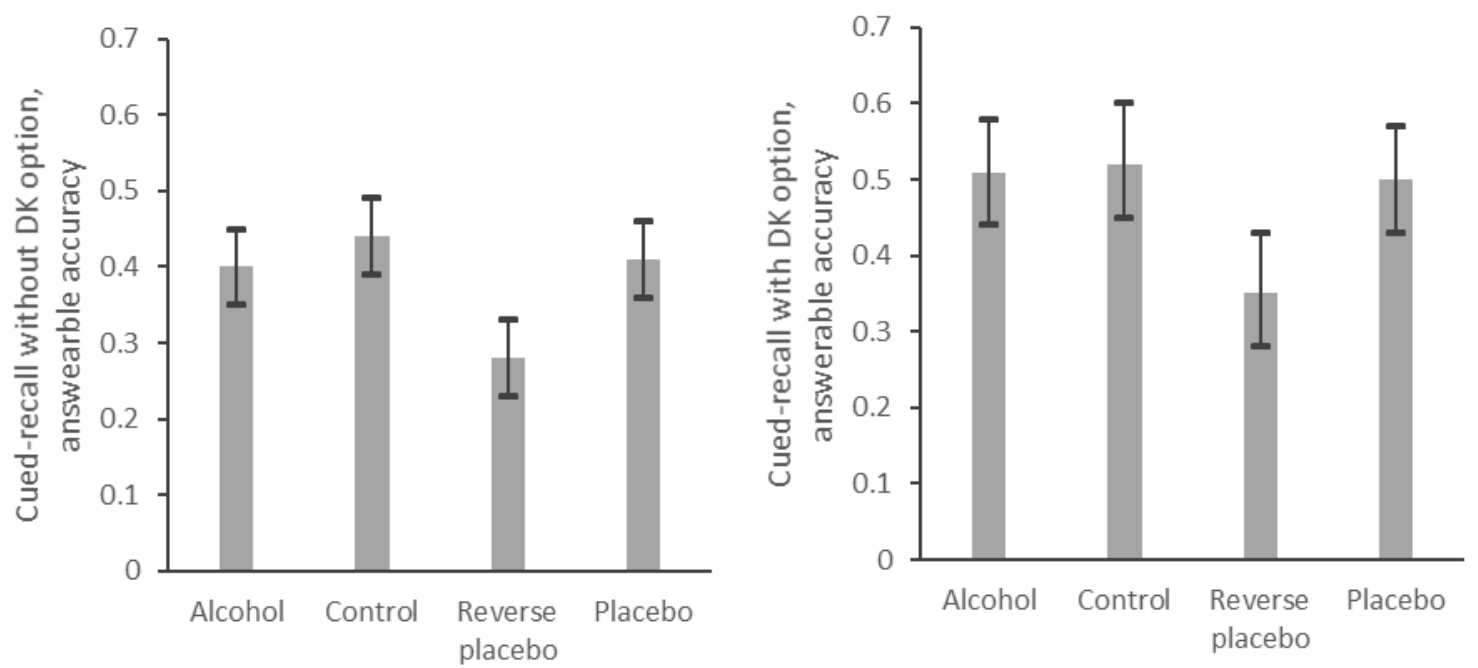

Figure 1. Alcohol by expectancy interactions for accuracy during cued-recall with and without DK option. Error bars are $95 \%$ CIs on group means.
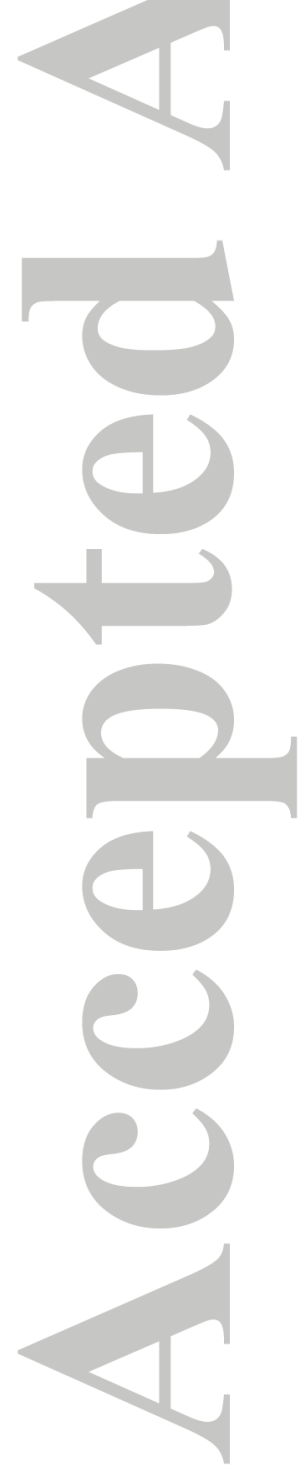

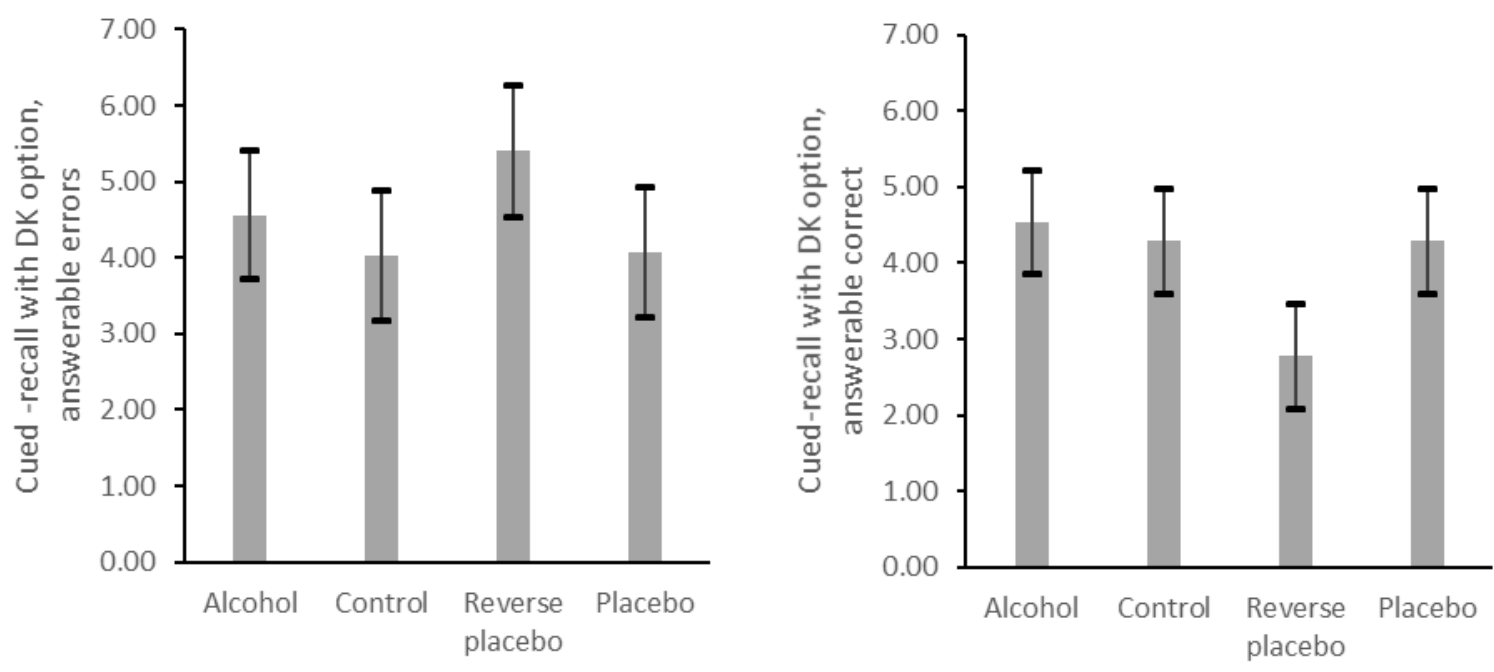

Figure 2. Alcohol by expectancy interactions for errors and correct responses to answerable questions during cued-recall with DK option. Error bars are 95\% CIs on group means.
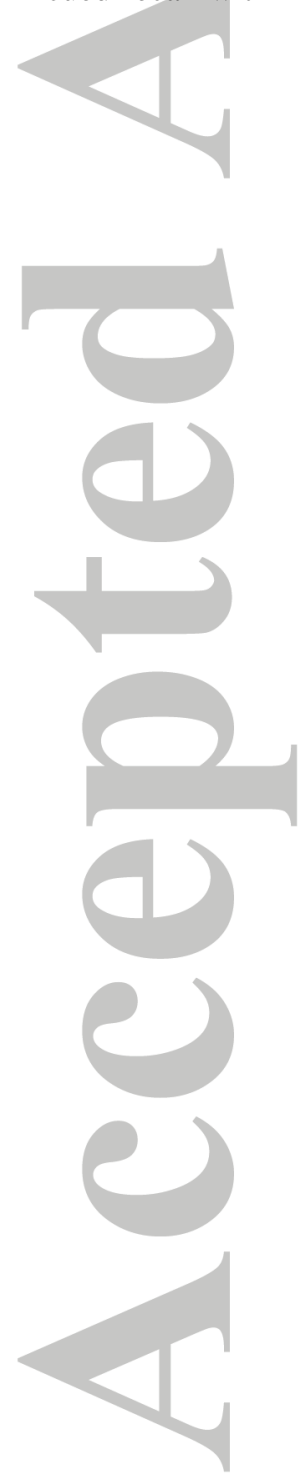